\title{
Effect of nerve injury on the number of dorsal root ganglion neurons and autotomy behavior in adult Bax-deficient mice
}

This article was published in the following Dove Press journal:

Journal of Pain Research

30 August 2017

Number of times this article has been viewed

\section{Chuang Lyu ${ }^{1,2}$ \\ Gong-Wei Lyu ${ }^{3}$ \\ Aurora Martinez ${ }^{4}$ \\ Tie-Jun Sten Shi ${ }^{4}$}

'State Key Laboratory of Veterinary Biotechnology, Harbin Veterinary Research Institute of Chinese Academy of Agricultural Sciences, Harbin, People's Republic of China; ${ }^{2}$ Department of Neuroscience, Karolinska Institutet, Stockholm, Sweden; ${ }^{3}$ Department of Neurology, Ist Hospital of Harbin Medical University, Harbin, People's Republic of China; ${ }^{4}$ Department of Biomedicine, University of Bergen, Bergen, Norway
Correspondence: Tie-Jun Sten Shi Department of Biomedicine, University of Bergen, Jonas Lies vei 91, 5009 Bergen, Norway

Tel +47 45392855

Email tiejun.shi@uib.no
Background: The proapoptotic molecule BAX, plays an important role in mitochondrial apoptotic pathway. Dorsal root ganglion (DRG) neurons depend on neurotrophic factors for survival at early developmental stages. Withdrawal of neurotrophic factors will induce apoptosis in DRG neurons, but this type of cell death can be delayed or prevented in neonatal Bax knockout (KO) mice. In adult animals, evidence also shows that DRG neurons are less dependent upon neurotrophic factors for survival. However, little is known about the effect of Bax deletion on the survival of normal and denervated DRG neurons in adult mice.

Methods: A unilateral sciatic nerve transection was performed in adult Bax KO mice and wild-type (WT) littermates. Stereological method was employed to quantify the number of lumbar-5 DRG neurons 1 month post-surgery. Nerve injury-induced autotomy behavior was also examined on days 1, 3, and 7 post-surgery.

Results: There were significantly more neurons in contralateral DRGs of KO mice as compared with WT mice. The number of neurons was reduced in ipsilateral DRGs in both KO and WT mice. No changes in size distributions of DRG neuron profiles were detected before or after nerve injury. Injury-induced autotomy behavior developed much earlier and was more serious in KO mice.

Conclusion: Although postnatal death or loss of DRG neurons is partially prevented by Bax deletion, this effect cannot interfere with long-term nerve injury-induced neuronal loss. The exaggerated self-amputation behavior observed in the mutant mice indicates that Bax deficiency may enhance the development of spontaneous pain following nerve injury.

Keywords: apoptosis, axotomy, cell death, chronic pain, unbiased counting method, sensory neurons

\section{Introduction}

The potential molecular mechanisms of neuronal death have not been conclusively elucidated, but it can be concluded that activation of apoptotic pathway, at least in part, is involved. ${ }^{1,2} \mathrm{BAX}$, a member of Bcl-2 family, is a proapoptotic molecule which can powerfully regulate the programmed death of neurons in both the peripheral and central nervous systems. ${ }^{3,4}$ BAX is expressed during the development of the nervous system as well as in adult animals. ${ }^{5-7}$ Bax knockout (KO) mice have recently been used for studying programmed cell death (PCD). Bax KO mice grow normally and are externally indistinguishable from wild-type (WT) mice, although the mutant mice display hyperplasia of lymphocytes and ovarian granulosa cells and unusual testicular degeneration. ${ }^{8}$ In the brain, the absence of PCD of Purkinje cells and external granular cells was observed in Bax $\mathrm{KO}$ mice during early postnatal development. ${ }^{9} \mathrm{BAX}$ was also reported to be critical for the elimination of olfactory bulb neurons in adult 
animals. ${ }^{10}$ In the neonatal mice, Bax deficiency prevented death of motor neurons in the spinal cord after sciatic nerve transection (axotomy), ${ }^{11}$ despite the surviving motor neurons undergoing severe atrophy. ${ }^{12}$ Furthermore, peripheral nerve injury causes significant neuronal loss and changes in neuropeptide expression in dorsal root ganglia (DRGs), and the injury-induced dramatic alteration of DRGs may lead to deficiency of sensory recovery. ${ }^{13}$ Interestingly, there is evidence showing that the process of neuronal PCD in DRGs during developmental stages is blocked in Bax $\mathrm{KO}$ mice. ${ }^{3}$

Peripheral transection of sciatic nerve may induce autotomy behavior in animals, such as licking, scratching and self-mutilation of the denervated limb. ${ }^{14}$ Wall et al ${ }^{14}$ have further demonstrated that different types of peripheral nerve lesions cause different degrees of autotomy. ${ }^{15}$ Thus, complete transection induced the most serious autotomy. Less autotomy developed after simple nerve ligation, and no or only minimal autotomy was detected following a crush or partial nerve injury. ${ }^{15}$ The severity of autotomy behavior represents difference in diverse mouse strains after axotomy, suggesting that genetic factors may also determine the variability in the development of abnormal sensations. ${ }^{16}$ Autotomy in rodents is regarded as spontaneous pain rather than simple numbness proved by the pharmacological evidence, in which this behavior can be prevented or suppressed by drug treatment, such as anticonvulsants, antidepressants, N-methyl-D-aspartate (NMDA) receptor antagonists or $\mathrm{Mg}^{2+}$ ions. ${ }^{17-19}$ Surgical treatment has also been used clinically, for example, dorsal column stimulation and dorsal root entry zone lesions, to suppress autotomy. ${ }^{20,21}$

It is still unknown whether the Bax deficiency can affect the survival of primary sensory neurons under normal and neuropathic pain conditions in adult animals. To address these questions, in the present study, adult $\operatorname{Bax} \mathrm{KO}$ mice were utilized for further investigation.

\section{Materials and methods}

All animals used in this study were kept under standard conditions on a 12-hour day/night cycle with free access to food and water. The experiments were carried out according to the ethical guidelines of the International Association for the Study of Pain and were approved by Norra Djurförsöksetiska Nämnd (Northern Stockholm Experimental Animal Ethical Committee; N150/11). All efforts were made to minimize the number of animals used and their suffering.

\section{Animals and surgery}

Transgenic lines were maintained as homozygous mutants. Bax KO mice were purchased from Jackson ImmunoResearch
Laboratories, Inc. (West Grove, PA, USA) and maintained on a C57BL/6J genetic background. ${ }^{8}$ Heterozygous male and female mice were obtained by mating of KO and WT mice. Then, the heterozygous mice were further mated to obtain more KO mice. ${ }^{22}$ Genotyping was performed by polymerase chain reaction (PCR) of genomic DNA extracted from the mouse tail as described in a previous study. ${ }^{8}$ The primers for PCR were as follows: Bax exon $5^{\prime}$ forward primer (5'-CCG CTT CCA TTG CTC AGC GG-3'), Bax intron 5' reverse primer (5'-TGA TCA GAA CCA TCA TG-3'), Neo reverse primer (5'-GTT GAC CAG AGT GGC GTA GG-3').

Four-month-old $\mathrm{KO}$ and WT male mice were deeply anesthetized with sodium pentobarbital (Mebumal; $20 \mathrm{mg} / \mathrm{kg}$, intraperitoneal injection). The left sciatic nerve was exposed, and axotomy was performed at "mid-thigh" level. A 5-mm portion of the nerve was resected to prevent regeneration. ${ }^{23}$ For behavior study, the animals were allowed to survive for 7 days after surgery. For quantifying the number of DRG neurons, animals were allowed to survive for 1 month after axotomy.

To avoid suffering caused by autotomy, only mice with low autotomy score (less than 6) after nerve injury were included in the further quantifying experiments. To minimize the number of animals, the following basic principles and guidelines have been adopted: 1) animal experiments were designed and performed in accordance with "3R" principle which is reducing, replacing and refining the use of animals; 2) mice were fed and looked after strictly to avoid the animal death caused by unexpected factors and 3) animals were under strict monitoring, the most aggressive ones were fed separately once they threatened the lives of other mice in the same cage. The analysis of sample size was based on the previous studies on autotomy, and around 15 animals were used in either the injured or control group. ${ }^{16,24}$

To reduce the suffering in animals, the mice that developed autotomy behavior with a high score (more than 11) were sacrificed immediately. Furthermore, $\mathrm{CO}_{2}$ was used for quick and humane sacrifice of the animals for experiments.

\section{Autotomy test}

Autotomy behavior of animals was scored at 10 am daily and performed until the 7 th day after axotomy ( $n=15$ for $\mathrm{KO}$ mice and $\mathrm{n}=14$ for WT mice, respectively). The serious degree was graded by a scoring scale described ${ }^{14}$ as follows: one point was assigned to removal of one or more nails; one point was added when a distal half of each toe was injured and one extra point was added for a proximal half of each toe. Finally, a point was added for the distal and proximal 
halves of the hindpaw. The maximum score for this scoring scale was 13 points. Greater or equal to score 6 was assumed to be serious autotomy.

Onset time of autotomy was defined as the day on which autotomy score reached 1 for the first time. Several time points, i.e., 0, 1, 3 and 7 days were chosen for inspecting the autotomy behavior of animals. Recording was conducted objectively. All the processes were completed by the same person who was blind to the experimental design.

\section{Tissue preparation}

One month after axotomy, animals were deeply anesthetized with sodium pentobarbital (Mebumal; $50 \mathrm{mg} / \mathrm{kg}$, intraperitoneal injection) and transcardially perfused with $20 \mathrm{~mL}$ of warm saline $\left(0.9 \% ; 37^{\circ} \mathrm{C}\right)$, followed by $20 \mathrm{~mL}$ of a warm mixture of paraformaldehyde $\left(4 \% ; 37^{\circ} \mathrm{C}\right)$ with $0.4 \%$ picric acid in $0.16 \mathrm{M}$ phosphate buffer ( $\mathrm{pH} 7.2$ ) and then by $50 \mathrm{~mL}$ of the same, but ice-cold fixative. After perfusion, both ipsilateral and contralateral lumbar (L)-5 DRGs of KO (n $=7)$ and WT $(n=7)$ mice were dissected and postfixed in the same fixative for $90 \mathrm{~min}$ at $4^{\circ} \mathrm{C}$ and subsequently stored in $10 \%$ sucrose in phosphate-buffered saline (PBS; $\mathrm{pH} 7.4$ ) containing 0.01\% sodium azide (Sigma-Aldrich Co., St Louis, MO, USA) and $0.02 \%$ bacitracin (Sigma-Aldrich Co.) at $4{ }^{\circ} \mathrm{C}$ for 2 days. The $\mathrm{L} 5 \mathrm{DRG}$ were then randomly rotated around their longitudinal axis and embedded with optimum cutting temperature compound (Tissue Tek; Miles Laboratories, Elkhart, IN, USA), cut into 14 or $30-\mu$ m-thick serial sections in a cryostat (Microm, Heidelberg, Germany) and mounted onto Superfrost Plus Microscope Slides (Thermo Fisher Scientific, Waltham, MA, USA). Finally, all the sections were counterstained in $0.001 \%$ propidium iodide $(\mathrm{PI}$; $0.001 \% \mathrm{w} / \mathrm{v}$; Sigma-Aldrich Co.).

\section{Immunohistochemistry}

Sections were dried at room temperature (RT) for $30 \mathrm{~min}$ and rinsed with PBS for $15 \mathrm{~min}$. Sections (14- $\mu \mathrm{m}$-thick) were incubated for 24 hours at $4^{\circ} \mathrm{C}$ in a humid chamber with rabbit anti-calcitonin gene-related peptide (CGRP) $(1: 10,000)^{25}$ antiserum diluted in PBS containing $0.2 \%(\mathrm{w} / \mathrm{v})$ bovine serum albumin (BSA) and $0.03 \%$ Triton X-100. Immunoreactivity was visualized using the tyramide signal amplification system (TSA Plus; NEN Life Science Products, Boston, MA, USA). Briefly, the slides were rinsed with Tris- $\mathrm{HCl} / \mathrm{NaCl} /$ Tween-20 (TNT) buffer (0.1 M Tris-HCl, pH 7.5; 0.15 M NaCl; 0.05\% Tween-20) for $15 \mathrm{~min}$ at RT, blocked with Tris- $\mathrm{HCl} / \mathrm{NaCl} /$ DuPont blocking reagent (TNB) buffer $(0.1 \mathrm{M}$ Tris- $\mathrm{HCl}$; $\mathrm{pH} 7.5 ; 0.15 \mathrm{M} \mathrm{NaCl} ; 0.5 \%$ DuPont blocking reagent) for $30 \mathrm{~min}$ at RT followed by a 30-min incubation with horse- radish peroxidase-labeled swine anti-rabbit antibody (1:200; Dako Denmark A/S, Glostrup, Denmark) diluted in TNB buffer. After a quick wash in TNT buffer, all sections were exposed to biotinyl tyramide fluorescein $(1: 100)$ diluted in amplification diluent for $10 \mathrm{~min}$ and finally washed in TNT buffer for $30 \mathrm{~min}$. Sections to be used for counting (with nucleus) counterstained with PI were mounted with glycerol/ PBS (9:1) containing 2.5\% DABCO (1,4-diazabicyclo[2.2.2] octane; Sigma-Aldrich Co.).

\section{Quantitative analysis}

The number of DRG neurons from axotomized mice was measured using stereological method as described in our previous study ${ }^{26}$ Every third section $(30-\mu \mathrm{m}$-thick) was systematically sampled with a random starting point. Between 8 and 14 sections were examined for each ganglion. The counting was performed using a Sarastro 1000 (Molecular Devices LLC, Sunnyvale, CA, USA) confocal laser scanning system. Images were recorded with a $100 \times / 1.25$ oil immersion objective and stored in a computer for subsequent analysis in Image Space Software (Molecular Devices LLC). The Cavalieri method was used to quantify the volume of the DRGs. ${ }^{27}$ The cross-sectional area of each ganglion was measured with a $4 \times$ air objective by using Image Space Software. Axial scan was used to measure the thickness of sections in a random, systematic fashion across each section with the $100 \times$ objective. The ganglion volume was calculated by multiplying the mean cross-sectional area, the mean section thickness and the number of sections of the DRGs. A mean of 39 disectors was analyzed in each ganglion. With a random starting point in each section, every fifth field was systematically sampled. At each location, optical sectioning was performed with the confocal laser scanning system $(100 \times / 1.25$ oil objective). The starting point, which derived from a z-scan, was set at $3-5 \mu \mathrm{m}$ below the section surface. From this point, 13 consecutive optical sections were recorded by using a $z$-axis step size of $1 \mu \mathrm{m}$. An unbiased counting frame with an area of $10,400 \mu \mathrm{m}^{2}$ was presented by the computer, and all neurons with a nucleolus in the starting plane or in the guard volume were disregarded. In the following $12 \mathrm{sec}$ tions, all neurons with a distinct nucleolus appearing inside the counting frame were counted. By using optical disector, an average of 120 neurons was sampled in each ganglion. The neuron density was calculated as the sum of all neurons counted divided by the summed volume of all disectors, i.e., the number of neurons was calculated as the product of the DRG volume and the numerical density.

The size distribution of neuron profiles (NPs) with a visible nucleus, in the ipsilateral and contralateral DRGs of 
$\mathrm{KO}(\mathrm{n}=7)$ and WT $(\mathrm{n}=7)$ mice 1 month after axotomy, was measured using the Sarastro 1000 confocal laser scanning system. NPs were classified into small, medium-sized and large ones based on the previous studies. ${ }^{23,28}$

\section{TUNEL analysis}

The sections were randomly selected and stained with a terminal deoxynucleotidyl transferase (TdT)-mediated dUTP nick end labeling (TUNEL) kit as previously reported. ${ }^{29}$ In brief, sections were washed in PBS and subsequently stained with PI for $15 \mathrm{~min}$. The TUNEL technique was used to detect single/double-strand breaks. Sections were incubated with TdT buffer ( $0.2 \mathrm{M}$ potassium cacodylate, $21 \mathrm{mM}$ Tris- $\mathrm{HCl}$, BSA $0.25 \mathrm{mg} / \mathrm{mL}, \mathrm{pH} 6.6)$ containing TdT (0.25 U/mL), biotin-16-dUTP (0.02 $\mathrm{mM})$ and cobalt chloride solution $(1 \mathrm{mM})$ in a humid atmosphere at $37^{\circ} \mathrm{C}$ for $60 \mathrm{~min}$. The reaction was terminated by transferring the slides to citrate buffer (containing, in mM: sodium chloride, 300; sodium citrate, 30) for $15 \mathrm{~min}$ at RT. After $15 \mathrm{~min}$ in $2 \% \mathrm{BSA}$, the sections were incubated with extra avidin fluorescein isothiocyanate (1:100) in PBS for $30 \mathrm{~min}$, rinsed and mounted. An average of 10 sections from each DRG $(n=5)$ was examined, and the TUNEL-positive cells were analyzed using the Sarastro 1000 confocal microscopy system.

\section{Statistical analysis}

Autotomy behavior scoring, size distribution of NPs and the number of DRG neurons quantifying data were expressed as mean \pm standard error of the mean (SEM) and mean $\pm \mathrm{SD}$, respectively. Differences were analyzed by unpaired twotailed $t$-test using GraphPad Prism 6.01 software (GraphPad Software, Inc., La Jolla, CA, USA).

\section{Results}

\section{Genotyping and autotomy behavior evaluation}

Tail-biopsy genotyping was used for selecting Bax KO mice (Figure 1A). A single band (507 bp) was detected in $\mathrm{KO}$ mice, and one band (304 bp) was found in WT littermates, whereas two bands (304 bp and $507 \mathrm{bp}$ ) were detected in heterozygous mice.

Autotomy behavior was observed in both $\mathrm{KO}$ and WT mice after axotomy. In the WT group, the proportion (i.e., percentage) of autotomized mice on days 1 and 3 post-surgery was $0 \%(0 / 14)$ and $21 \%(3 / 14)$, respectively (Figure 1B). In the $\mathrm{KO}$ group, autotomy behavior was first detected on day 1 post-surgery, and the proportion was $27 \%$ (4/15) and $60 \%$ (9/15) on days 1 and 3 , respectively (Figure 1B).
At the last time point (day 7) of the behavior test, the proportion and the score of autotomy in WT mice were $29 \%$ (4/14) and $1.1 \pm 0.6$ (Figure 1C and D), while 80\% (12/15) and $6.6 \pm 1.4$ (Figure $1 \mathrm{C}$ and $\mathrm{D}$ ), respectively, were measured in $\mathrm{KO}$ mice. Thus, axotomy induced more severe autotomy behavior in KO mice than in WT mice. In the WT group, the removal of toe nails was seen in a few animals (Figure 2A); however, damaged distal and proximal half-phalanges, in addition to the removal of toe nails, were detected in $\mathrm{KO}$ mice (Figure 2B).

\section{Number of DRG neurons after axotomy}

One month after axotomy, the number of DRG neurons was significantly decreased in ipsilateral DRGs compared with contralateral ones in both $\mathrm{KO}$ and WT mice. In the contralateral DRGs, 12,061 \pm 1152 and 10,254 \pm 1198 neurons ( $\mathrm{n}=7$ DRGs per group) were counted in KO and WT mice, respectively. In the ipsilateral DRGs, $6523 \pm 1463$ and 5148 \pm 1112 neurons were counted in KO and WT mice, respectively (Figure 3A). Statistically, there were significantly more neurons in the contralateral DRGs of KO mice as compared with WT mice $(12,061 \pm 1152$ vs. $10,254 \pm 1198 ; p<0.05)$. However, no significant difference was seen in the ipsilateral DRGs between KO and WT mice $(6523 \pm 1463$ vs. $5148 \pm$ 1112; $p>0.05)$.

In WT control animals, PI-labeled neurons (Figure 3B; arrows) and satellite cells (Figure 3B; arrowheads) exhibited a strong and typical cytoplasmic and nuclear fluorescence (red; Figure 3B), whereas CGRP-like immunoreactivity (LI) was exclusively present in the cytoplasm and fibers (green; Figure 3B). CGRP-LI was detected in small (I; Figure 3B), medium (II; Figure 3B) and large (III; Figure 3B) NPs. TUNEL staining was used to examine the apoptotic neurons in the axotomized DRGs. TUNEL-positive signals were found in both neuronal (thick arrow; Figure 3C) and satellite cells (arrows; Figure 3C), but the proportion for neurons was very low, i.e., less than $0.1 \%$ was seen in both $\mathrm{KO}$ and WT mice.

\section{Size distribution of DRG NPs}

To investigate the size distribution, the NPs were classified into small (a somal area of 100-600 $\mu^{2}$ ), medium-sized (a somal area of $\left.600-1400 \mu \mathrm{m}^{2}\right)$ and large ones $\left(>1400 \mu \mathrm{m}^{2}\right)$ as described in our previous study. ${ }^{23}$ In the contralateral DRGs, $70 \pm 10 \%, 27.5 \pm 10 \%$ and $2.5 \pm 2 \%$ of NPs were small, medium and large in $\mathrm{KO}$ mice, while $67 \pm 7 \%, 31 \pm 5 \%$ and $2 \pm$ $1 \%$ were detected in WT mice, respectively (Figure 4A and B). Furthermore, in the ipsilateral DRGs of KO mice, $69.5 \pm 7 \%$, 
A

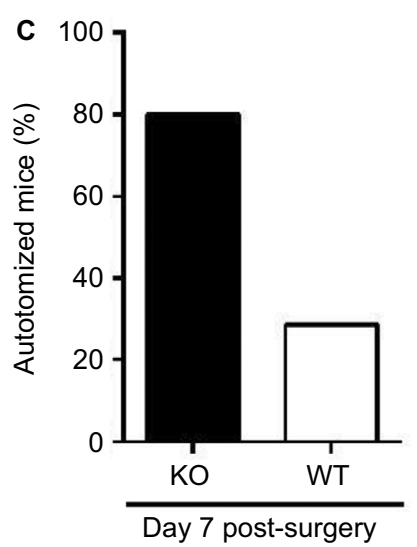

B

D
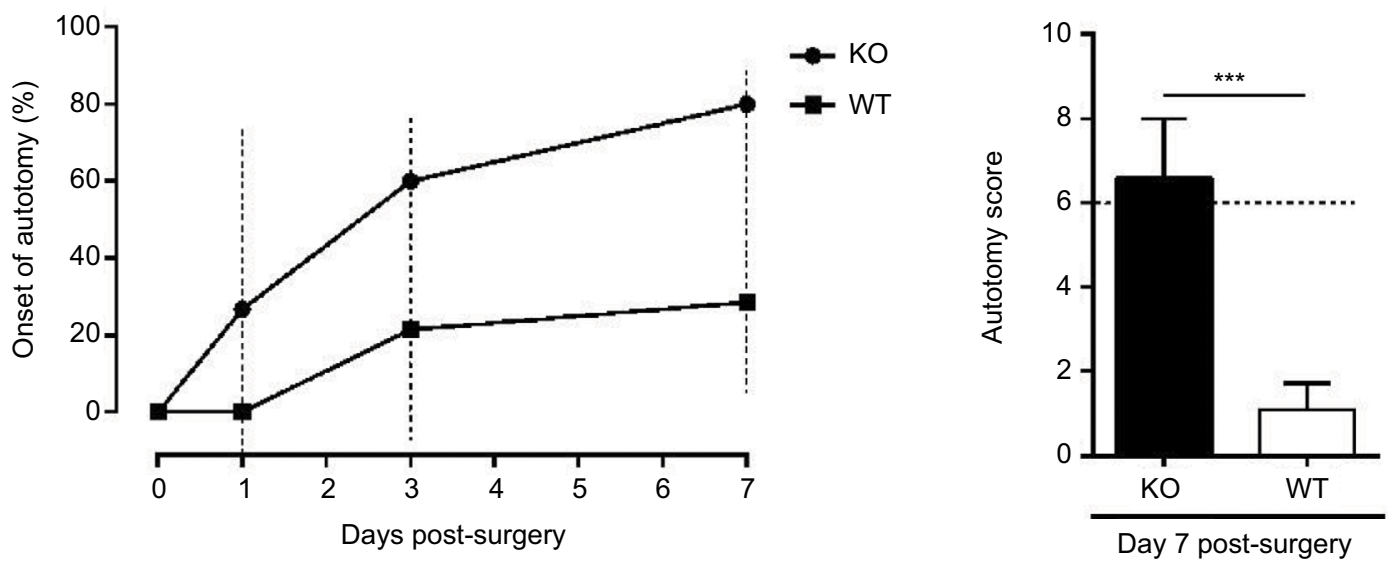

Figure I Genotyping and autotomy evaluation after axotomy.

Notes: (A) Identification of KO (-l-), heterozygous (+l-) and WT (+/+) mice by PCR. (B) Onset of autotomy observed on days $0,1,3$ and 7 post-surgery in KO and WT mice. (C) Percentage of autotomized mice on day 7 post-surgery. (D) Representation of the severity of autotomy by score in KO and WT mice on day 7 post-surgery. $* * * 0<0.001$.

Abbreviations: KO, knockout; PCR, polymerase chain reaction; WT, wild-type.
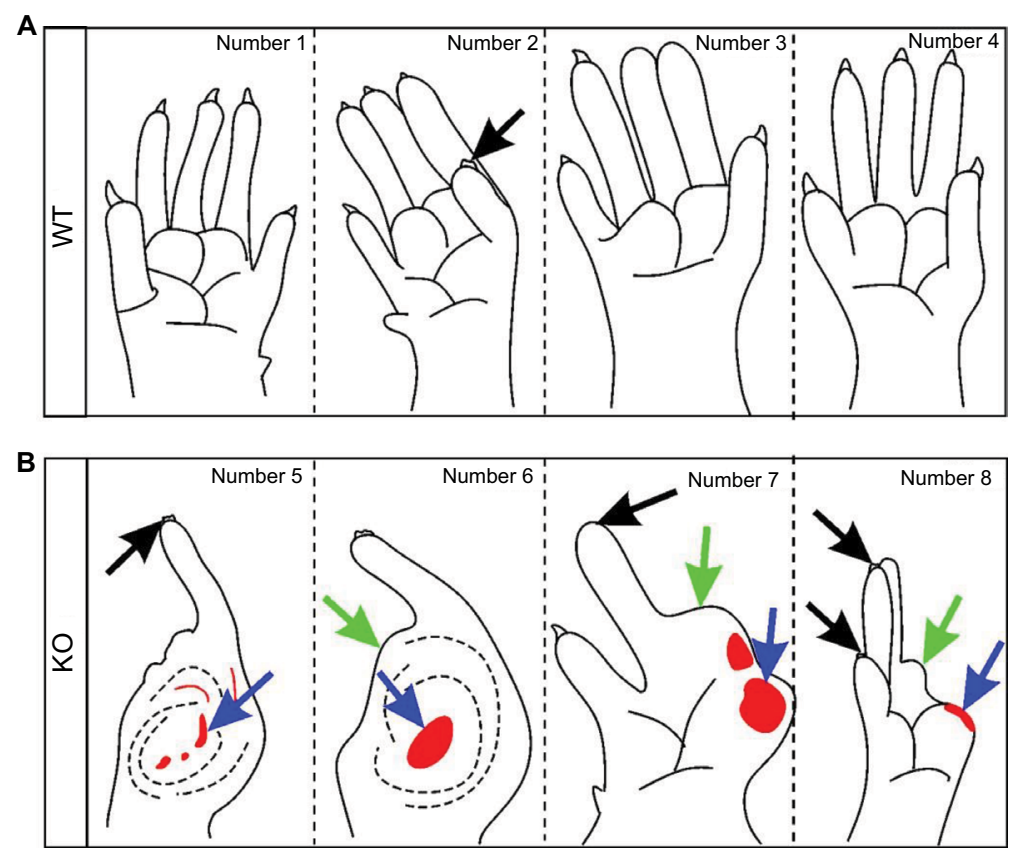

Figure 2 Autotomy detected 7 days after axotomy.

Notes: (A, B) Schematics of autotomy occurred on the hindpaws of WT (A) and KO (B) mice. The numbers I-8 represent different individuals in the experiments. Black and green arrows indicate the injury of nails and toes, respectively, and blue arrows indicate bleeding spots.

Abbreviations: KO, knockout; WT, wild-type. 
A
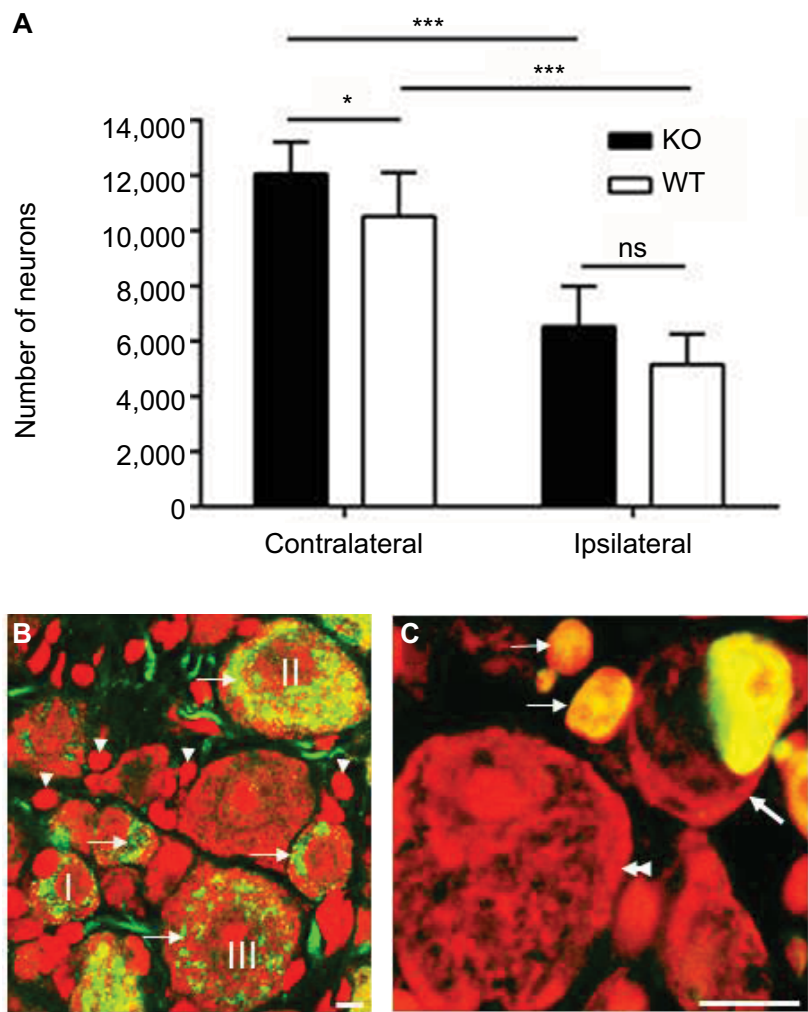

Figure 3 Neuronal number of L5 DRGs I month after axotomy.

Notes: (A) The number of neurons is significantly decreased in the ipsilateral DRGs as compared with the contralateral DRGs in both KO $(n=7)$ and WT $(n=7)$ mice, respectively. There are significantly more neurons in the contralateral DRGs in KO mice than in WT mice. The number of neurons in the ipsilateral DRGs of KO mice is similar to that of WT mice. $*_{p}<0.05$; *** $p<0.00 \mathrm{I}$; ns $p>0.05$. (B) Immunofluorescence micrograph presents double labeling with CGRP anti-serum (green) and PI (red) in intact DRG in WT mouse. PI-labeled neurons (arrows) and satellite cells (arrowheads) exhibit a strong and typical cytoplasmic and nuclear fluorescence, whereas CGRP-LI is exclusively present in the cytoplasm and fibers (green). CGRP-LI is detected in small (I), medium (II) and large (III) NPs. (C) Immunofluorescence micrograph presents TUNEL-positive cells in axotomized DRG in WT mouse. Thick arrow points to a TUNEL-positive neuron, thin arrows point to TUNEL-positive satellite cells and a double arrowhead points to a TUNELnegative neuron. Scale bars, $B=5 \mu \mathrm{m}$ and $C=10 \mu \mathrm{m}$.

Abbreviations: CGRP, calcitonin gene-related peptide; DRG, dorsal root ganglion; KO, knockout; L5, lumbar-5; NPs, neuron profiles; ns, no significance; PI, propidium iodide; TUNEL, terminal deoxynucleotidyl transferase-mediated dUTP nick-end labeling; WT, wild-type.

$29 \pm 6 \%$ and $1.5 \pm 2 \%$ of NPs were small, medium and large, and $65.5 \pm 11 \%, 32.5 \pm 3 \%$ and $2 \pm 2 \%$ of NPs were found in WT mice, respectively (Figure 4C and D). The proportion of the NPs for each size group has no significant difference between WT and KO mice ( $p>0.05$; Figure 4B and D).

\section{Discussion}

Peripheral nerve axotomy can induce neuroma and autotomy behavior in both rats and mice. This behavior depends on input from the neuroma which is developed at proximal end of the injured nerve, and where ectopic action potentials are generated. ${ }^{30}$ Autotomy behavior is often considered as a sign of spontaneous pain, which is one of the symptoms of neuropathic pain. ${ }^{15,31,32}$ The time course and degree of autotomy behavior depends on the types of injury. It has been reported that section of the nerve and encapsulation of its proximal stump in a polythene tube caused the most serious autotomy, whereas a crush lesion induced only minimal autotomy. ${ }^{14}$ Autotomy behavior was found occurring within the 1 st week after axotomy with the ratio of $6 \%$, then continued even to the 7 th week with the ratio of $75 \%$ in rats. ${ }^{33}$ Meanwhile, there was considerable variation between different individuals in the probability of onset of autotomy. ${ }^{33}$ The autotomy score was recorded no more than 1 on the 7 th day, and reached up to 6 at the 7 th week. ${ }^{33}$ Furthermore, Persson et al ${ }^{14}$ performed the transection of sciatic and saphenous nerve on different inbred strains of adult mice (10-20 weeks), including AKR/J, $\mathrm{C} 3 \mathrm{H} / \mathrm{HeJ}, \mathrm{C} 57 \mathrm{BL} / 6 \mathrm{~J}, \mathrm{C} 58 / \mathrm{J}$ and CBA/J. Autotomy behavior was observed in all of those strains but with different intensities reflected by the autotomy scores. Therefore, autotomy behavior developed has apparent species specificity.

In this study, 7-day axotomy was chosen as the time window duration for studying autotomy behavior to alleviate the suffering of animals. The results showed that WT mice developed low autotomy scores after surgery, which was consistent with the previous findings. ${ }^{15}$ Surprisingly, a more serious autotomy behavior was detected in $\mathrm{KO}$ mice. The mean onset of autotomy was significantly earlier, and autotomy scores were much higher in KO mice than in WT mice. It has been shown that high autotomy score was developed in rats after dorsal root ganglionectomy (DRGn), and autotomy can be largely ( $83 \%$ ) blocked by a high dose of NMDA receptor antagonist 2 days after DRGn, indicating a role of NMDA-induced excitotoxic stimuli in autotomy. ${ }^{16}$ The outcome of drug treatment only lasted for 2 days but not longer time, indicating that the excitatory effect of NMDA, which is largely induced in the nerve system after injury of DRGs, is time dependent. Furthermore, the evidence that retinal ganglion cells were killed by NMDA-induced excitotoxic stimuli, but not after optic nerve crush in Bax KO mice, indicated that neuronal cell death in various models is induced through activation of different death pathways. ${ }^{14,15}$ It further demonstrated that, in NMDA-induced excitotoxic model, cell death was independent of Bax signaling pathway. ${ }^{14}$ Consistent with previous findings, our results showed that lack of BAX failed to prevent neuronal loss and suggested that this loss was Bax independent, especially after a long-term and severe nerve injury. The enhanced autotomy behavior observed in this study indicated that neurotoxicity of endogenous NMDA 
A

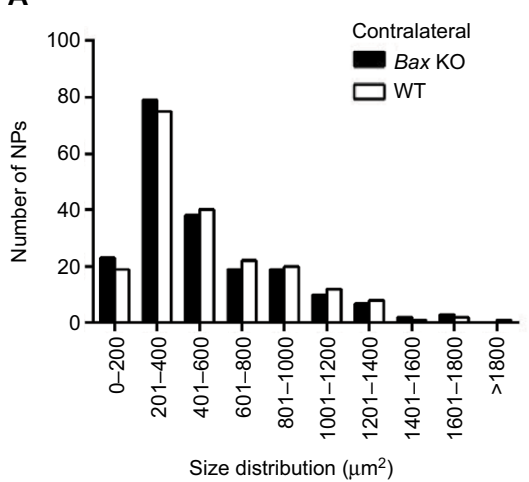

C

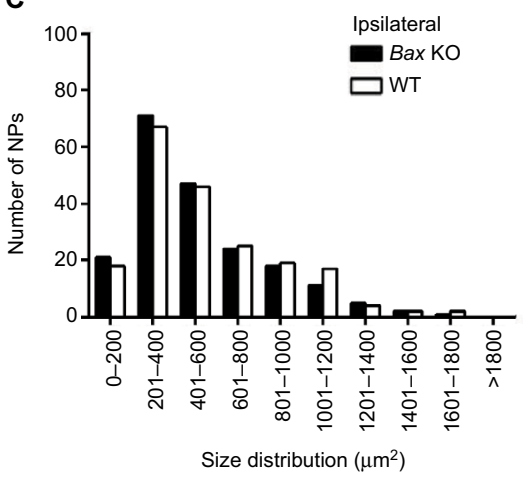

B

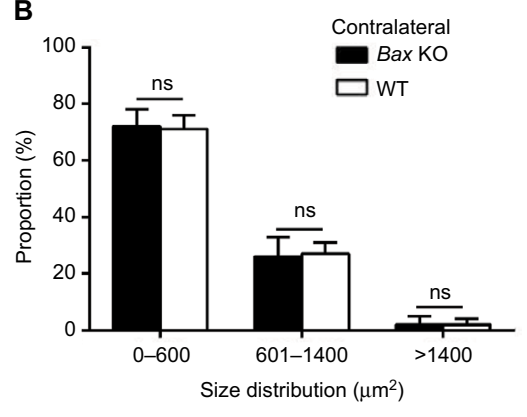

D

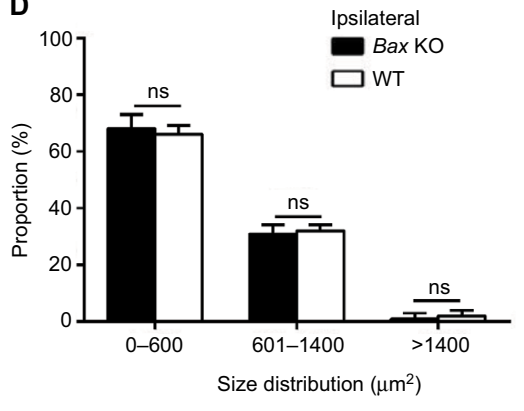

Figure 4 Soma size distribution of DRG NPs I month after axotomy.

Notes: Size distribution of neuron profiles is not different between KO and WT mice in the contralateral (A, B) or the ipsilateral (C, D) DRGs, respectively. ns ( $p>0.05)$. $\mathrm{n}=200$ NPs per group.

Abbreviations: DRG, dorsal root ganglion; KO, knockout; NPs, neuron profiles; ns, no significance; WT, wild-type.

receptor might be increased in sensory neurons. It is expected that more interesting and important findings could be achieved if this clue can be traced in the future work.

In Bax KO mice, naturally occurring PCD is suppressed in a wide area of the nervous system, resulting in a supernumerary but mixed population of normal and atrophic neuronal cells during development. ${ }^{3,11}$ Spinal motor neurons can be rescued from apoptosis in neonatal $\mathrm{KO}$ mice after axotomy, which has been proved by previous studies. ${ }^{11,12}$ Moreover, DRG neurons were rescued on postnatal days 6-7 after axotomy. ${ }^{35}$ However, data in $\mathrm{KO}$ mice are still absent or incomplete on whether DRG neurons can be rescued in adult mice. In the present study, the effect of axotomy was investigated on 4-month-old $\mathrm{KO}$ mice. The results showed that the loss of neurons was not prevented in the axotomized DRGs of $\mathrm{KO}$ mice, indicating that Bax deficiency cannot antagonize the DRG neuronal loss caused by nerve injury. Compared with the extensive loss of neurons (around 50\% reduction), the number of the TUNEL-positive cell profiles was rare, i.e., less than $0.1 \%$, indicating that the number of apoptotic neuronal cell profiles detected by the current method, based on TdT-mediated dUDP nick end labeling of single/double-strand breaks, does not correlate well and ratio of apoptotic neurons may be underestimated. Accordingly, several reasons have been suggested: 1) apoptosis of neuronal cells actually occurs much earlier, for example, within a few days or even hours and therefore it can be difficult to detect; ${ }^{36-38}$ 2) it is known that TUNEL method is insufficient to detect the early phase of apoptosis ${ }^{36,37}$ and it is not suggested to be specific marker for apoptosis; ${ }^{38} 3$ ) it is expected that in nervous system many complex mechanisms behind neuronal death/loss exist, and in addition to apoptosis and necrosis, a mixture of these two forms of cell death may also take place. ${ }^{39-42}$ Significantly, more neurons in the contralateral DRGs were found in $\mathrm{KO}$ mice as compared with WT mice. This could be caused by decreased PCD of neurons during the developmental stage.

Regarding the size distribution of NPs, a certain degree of atrophy of DRG neurons, lacking the BAX protein, has been reported in previous studies. ${ }^{11,12,43}$ Inconsistent with these observations, our results showed no change on the soma size distributions between KO and WT mice in either the contralateral or ipsilateral DRGs. The possible reasons can be that the previous studies have been carried out on either embryonic, neonatal animals or young mice (maximum 4-week-old), whereas adult animals were used in our study. Sun and Oppenheim ${ }^{12}$ have also seen a similar size frequency of neuronal soma between $\mathrm{KO}$ and WT mice when they studied the facial motor neurons. The size of NPs was similar between KO and WT mice, suggesting that primary 
sensory neurons in adult KO mice may "recover" from atrophy. Interestingly, in a previous study, Bax overexpression has been shown to inhibit the effect of neurotrophic factors on sensory neurons. ${ }^{44}$ Thus, it is expected that when Bax is knocked down the effect of neurotrophic factor could be influenced, which may contribute to the "size recovery" of DRG NPs in KO mice.

\section{Conclusion}

This study showed a more serious autotomy behavior developed in Bax KO mice as compared with WT mice following sciatic nerve transection. These data also provide further evidence for a role of proapoptotic BAX in the development of abnormal sensation after nerve injury. Elimination of BAX failed to rescue the neuronal loss or influence the size distribution of DRG NPs, suggesting that in adult DRGs nerve injury-induced neuronal death or loss is Bax independent, and rather other key genes appear to be involved.

\section{Acknowledgments}

This work was supported by the Research Council of Norway, the KG Jebsen Foundation, and the China Scholarship Council (CSC) award to Dr. Chuang Lyu (Harbin Institute of Technology, 2013). We especially would like to thank Dr. Tomas Hökfelt for his generous sharing of the mutant mice and his laboratory facilities.

\section{Author contributions}

CL and GWL performed experiments. CL, AM and TJSS analyzed the data and wrote the manuscript. All authors contributed toward data analysis, drafting and critically revising the paper and agree to be accountable for all aspects of the work.

\section{Disclosure}

The authors report no conflicts of interest in this work.

\section{References}

1. Yuan J, Yankner BA. Apoptosis in the nervous system. Nature. 2000;407(6805):802-809.

2. Chang LK, Putcha GV, Deshmukh M, Johnson EM Jr. Mitochondrial involvement in the point of no return in neuronal apoptosis. Biochimie. 2002;84(2-3):223-231.

3. White FA, Keller-Peck CR, Knudson CM, Korsmeyer SJ, Snider WD. Widespread elimination of naturally occurring neuronal death in Baxdeficient mice. J Neurosci. 1998;18(4):1428-1439.

4. Krajewska M, Mai JK, Zapata JM, et al. Dynamics of expression of apoptosis-regulatory proteins Bid, Bcl-2, Bcl-X, Bax and Bak during development of murine nervous system. Cell Death Differ. 2002;9(2):145-157.

5. Krajewski S, Krajewska M, Shabaik A, Miyashita T, Wang HG, Reed JC. Immunohistochemical determination of in vivo distribution of Bax, a dominant inhibitor of Bcl-2. Am J Pathol. 1994;145(6):1323-1336.
6. Krajewski S, Mai JK, Krajewska M, Sikorska M, Mossakowski MJ, Reed JC. Upregulation of bax protein levels in neurons following cerebral ischemia. J Neurosci. 1995;15(10):6364-6376.

7. Vekrellis K, McCarthy MJ, Watson A, Whitfield J, Rubin LL, Ham J. Bax promotes neuronal cell death and is downregulated during the development of the nervous system. Development. 1997;124(6):1239-1249.

8. Knudson CM, Tung KS, Tourtellotte WG, Brown GA, Korsmeyer SJ. Bax-deficient mice with lymphoid hyperplasia and male germ cell death. Science. 1995;270(5233):96-99.

9. Jung AR, Kim TW, Rhyu IJ, et al. Misplacement of Purkinje cells during postnatal development in Bax knock-out mice: a novel role for programmed cell death in the nervous system? J Neurosci. 2008;28(11): 2941-2948.

10. Kim WR, Kim Y, Eun B, et al. Impaired migration in the rostral migratory stream but spared olfactory function after the elimination of programmed cell death in Bax knock-out mice. J Neurosci. 2007;27(52):14392-14403.

11. Kinugasa T, Ozaki S, Hamanaka S, Kudo N. The effects of sciatic nerve axotomy on spinal motoneurons in neonatal Bax-deficient mice. Neurosci Res. 2002;44(4):439-446.

12. Sun W, Oppenheim RW. Response of motoneurons to neonatal sciatic nerve axotomy in Bax-knockout mice. Mol Cell Neurosci. 2003;24(4):875-886.

13. Shi TJ, Hua XY, Lu X, et al. Sensory neuronal phenotype in galanin receptor 2 knockout mice: focus on dorsal root ganglion neurone development and pain behaviour. Eur J Neurosci. 2006;23(3):627-636.

14. Wall PD, Devor M, Inbal R, et al. Autotomy following peripheral nerve lesions: experimental anaesthesia dolorosa. Pain. 1979;7(2):103-111.

15. Minert A, Gabay E, Dominguez C, Wiesenfeld-Hallin Z, Devor M. Spontaneous pain following spinal nerve injury in mice. Exp Neurol. 2007;206(2):220-230.

16. Rubinstein RE, Deem KC, Jensen J, MacKinnon SE, Tung TH. Strain differences in autotomy in mice after peripheral nerve transection or repair. Microsurgery. 2003;23(4):363-368.

17. Seltzer Z, Tal M, Sharav Y. Autotomy behavior in rats following peripheral deafferentation is suppressed by daily injections of amitriptyline, diazepam and saline. Pain. 1989;37(2):245-250.

18. Feria M, Abad F, Sanchez A, Abreu P. Magnesium sulphate injected subcutaneously suppresses autotomy in peripherally deafferented rats. Pain. 1993;53(3):287-293.

19. Tseng SH. Suppression of autotomy by N-methyl-D-aspartate receptor antagonist (MK-801) in the rat. Neurosci Lett. 1998;240(1):17-20.

20. Gao XX, Ren B, Linderoth B, Meyerson BA. Daily spinal cord stimulation suppresses autotomy behavior in rats following peripheral deafferentation. Neuroscience. 1996;75(2):463-470.

21. Levitt M. Dysesthesias and self-mutilation in humans and subhumans: a review of clinical and experimental studies. Brain Res. 1985;357(3):247-290.

22. Park OH, Lee KJ, Rhyu IJ, et al. Bax-dependent and -independent death of motoneurons after facial nerve injury in adult mice. Eur J Neurosci. 2007;26(6):1421-1432.

23. Shi TJ, Tandrup T, Bergman E, Xu ZQ, Ulfhake B, Hokfelt T. Effect of peripheral nerve injury on dorsal root ganglion neurons in the C57 $\mathrm{BL} / 6 \mathrm{~J}$ mouse: marked changes both in cell numbers and neuropeptide expression. Neuroscience. 2001;105(1):249-263.

24. Katz J, Vaccarino AL, Coderre TJ, Melzack R. Injury prior to neurectomy alters the pattern of autotomy in rats. Behavioral evidence of central neural plasticity. Anesthesiology. 1991;75(5):876-883.

25. Lyu $\mathrm{C}$, Mulder J, Barde $\mathrm{S}$, et al. G protein-gated inwardly rectifying potassium channel subunits 1 and 2 are down-regulated in rat dorsal root ganglion neurons and spinal cord after peripheral axotomy. Mol Pain. 2015;11:44.

26. Shi TJ, Li J, Dahlstrom A, et al. Deletion of the neuropeptide Y Y1 receptor affects pain sensitivity, neuropeptide transport and expression, and dorsal root ganglion neuron numbers. Neuroscience. 2006;140(1):293-304.

27. Gundersen HJ, Jensen EB. The efficiency of systematic sampling in stereology and its prediction. J Microsc. 1987;147(pt 3):229-263. 
28. Dubovy P, Svizenska I, Vega JA. Non-specific cholinesterase activity in mouse spinal ganglia. The usefulness of histochemical study and image analysis for simple characterization of neuron subclasses. Cell Mol Biol. 1990;36(1):23-40.

29. Gavrieli Y, Sherman Y, Ben-Sasson SA. Identification of programmed cell death in situ via specific labeling of nuclear DNA fragmentation. J Cell Biol. 1992;119(3):493-501.

30. Zeltser R, Beilin B, Zaslansky R, Seltzer Z. Comparison of autotomy behavior induced in rats by various clinically-used neurectomy methods. Pain. 2000;89(1):19-24.

31. Zimmermann M. Pathobiology of neuropathic pain. Eur J Pharmacol. 2001;429(1-3):23-37.

32. Kauppila T. Correlation between autotomy-behavior and current theories of neuropathic pain. Neurosci Biobehav Rev. 1998;23(1):111-129.

33. Abdulla FA, Smith PA. Axotomy- and autotomy-induced changes in the excitability of rat dorsal root ganglion neurons. $J$ Neurophysiol. 2001;85(2):630-643.

34. Persson AK, Thun J, Xu XJ, et al. Autotomy behavior correlates with the DRG and spinal expression of sodium channels in inbred mouse strains. Brain Res. 2009;1285:1-13.

35. Kinugasa T, Kudo N, Ozaki S. Peripheral targets influence sensorymotor connectivity in the neonatal spinal cord: sciatic nerve axotomy in Bax-deficient mice. Neurosci Res. 2006;54(1):30-37.

36. Oberhammer F, Bursch W, Tiefenbacher R, et al. Apoptosis is induced by transforming growth factor-beta 1 within 5 hours in regressing liver without significant fragmentation of the DNA. Hepatology. 1993;18(5):1238-1246.
37. Cohen GM, Sun XM, Snowden RT, Dinsdale D, Skilleter DN. Key morphological features of apoptosis may occur in the absence of internucleosomal DNA fragmentation. Biochem J. 1992;286(pt 2): 331-334.

38. Enright H, Hebbel RP, Nath KA. Internucleosomal cleavage of DNA as the sole criterion for apoptosis may be artifactual. J Lab Clin Med. 1994;124(1):63-68.

39. Portera-Cailliau C, Price DL, Martin LJ. Excitotoxic neuronal death in the immature brain is an apoptosis-necrosis morphological continuum. J Comp Neurol. 1997;378(1):70-87.

40. Portera-Cailliau C, Price DL, Martin LJ. Non-NMDA and NMDA receptor-mediated excitotoxic neuronal deaths in adult brain are morphologically distinct: further evidence for an apoptosis-necrosis continuum. J Comp Neurol. 1997;378(1):88-104.

41. Martin LJ, Al-Abdulla NA, Brambrink AM, Kirsch JR, Sieber FE, Portera-Cailliau C. Neurodegeneration in excitotoxicity, global cerebral ischemia, and target deprivation: a perspective on the contributions of apoptosis and necrosis. Brain Res Bull. 1998;46(4):281-309.

42. Jesionek-Kupnicka D, Kordek R, Buczynski J, Liberski PP. Apoptosis in relation to neuronal loss in experimental Creutzfeldt-Jakob disease in mice. Acta Neurobiol Exp. 2001;61(1):13-19.

43. Suzuki H, Aoyama Y, Senzaki K, et al. Characterization of sensory neurons in the dorsal root ganglia of Bax-deficient mice. Brain Res 2010;1362:23-31.

44. Middleton G, Nunez G, Davies AM. Bax promotes neuronal survival and antagonises the survival effects of neurotrophic factors. Development. 1996;122(2):695-701.

\section{Journal of Pain Research}

\section{Publish your work in this journal}

The Journal of Pain Research is an international, peer reviewed, open access, online journal that welcomes laboratory and clinical findings in the fields of pain research and the prevention and management of pain. Original research, reviews, symposium reports, hypothesis formation and commentaries are all considered for publication.

\section{Dovepress}

The manuscript management system is completely online and includes a very quick and fair peer-review system, which is all easy to use. Visit http://www.dovepress.com/testimonials.php to read real quotes from published authors. 